\title{
Moving out of Sports: A Sociocultural Examination of Olympic Career Transitions
}

\section{Dean Barker ${ }^{1}$, Natalie Barker-Ruchti ${ }^{1}$, Steven Rynne ${ }^{2}$ and Jessica Lee $^{3}$}

1Department of Food and Nutrition, and Sport Science, University of Gothenburg, Box 300, 40530 Göteborg, Sweden

E-mail: Dean.Barker@ped.gu.se; Natalie.Barker@ped.gu.se

${ }^{2}$ School of Human Movement Studies, University of Queensland, 26B Blair Dr. St Lucia, QLD 4072, Australia

E-mail: srynne@hms.uq.edu.au

${ }^{3}$ School of Public Health, Griffith University, Gold Coast Campus, QLD 4222, Australia

E-mail: Jessica.Lee@griffith.edu.au

\begin{abstract}
This article outlines sociocultural learning theory, shows how this theory can be used to examine end-of-career athletic transitions, and stimulates discussion on the implications of this framework for sport professionals. The central question addressed is how learning in elite sport affects participation in activities beyond sporting settings. Data from in-depth, semi-structured interviews with three former Olympians are presented. The interpretation suggests that: 1) movement to new social settings involves abandoning some elements of athletic dispositions and developing new elements, 2) transitions are affected by prior learning in sport and the characteristics of new settings, and 3) learning in sporting environments is often unintentional or implicit. The results encourage practitioners to acknowledge the effort involved in developing new dispositions in different settings. They support a case-specific view of transitions where 'success' is considered in contextual terms. Further, the data highlight a need for sport professionals to recognize tacit learning.
\end{abstract}

Key words: Athletic Career Transitions, Life Skills, Olympians, Personal Identity, Sociocultural Learning Theory

\section{INTRODUCTION}

Career transitions have proven an enduring theme for those concerned with athlete welfare. Difficulties experienced by athletes as they adjust to life after sport have resulted in an

Reviewers: $\quad$ David Carless (Leeds Metropolitan University, UK) Natalia Stambulova (Halmstad University, Sweden) 
abundance of scholarship [1-5]. Despite evidence that suggests transitions are rarely as traumatic as is commonly believed [6], and notwithstanding research that indicates that career termination can be experienced very differently even within the same sport [7], investigators have suggested that some athletes do experience serious emotional and psychological distress [8,9] and face vocational challenges [10] on finishing sporting careers. These problems have led sport professionals to examine how transitions can be eased [e.g., 11-13]. While certainly not the only focus of transition literature, many have considered how athletes might be equipped with coping strategies and non-sport-specific skills - sometimes referred to as 'life skills' - during their careers [14, 15]. Central assumptions of this research are that athletes can acquire resources during training and competition and that athletes are able to utilize or transfer these resources to situations beyond sport. Alfermann and Stambulova:

An athlete's available resources are important. His or her ability to cope with the new situation (i.e., coping strategies and career planning after sports) and the social support system have great implications for adaptation...Athletes can use cognitive strategies, such as mental rehearsal of behavioral strategies in the future postcareer, or set goals for the postcareer. Anything that helps former athletes make plans for the future, pursue goals and be active is helpful. [16, p. 723]

In an instrumental manner, mental rehearsal and goal setting are seen to constitute techniques similar to stress management, teamwork and motivation and there is little wonder that theorists have claimed that there is potential for skill exchange between sport and other activities [17].

Despite intuitive appeal and general acceptance, the ideas that underpin these claims have been questioned. Theorists using a "sociocultural approach" - essentially a pedagogical perspective based on the premise that learners and social organizations exist in recursive or dialogic relation to one another - have pointed to conceptual shortcomings of acquisition and transfer theories and have proposed different approaches to transitions [18, 19]. Using this critique as a starting point, we explore the process of transition from elite sport to other areas of activity. The article has three specific objectives. The first is to outline an alternative theory of learning and career transitions based on a reconstruction metaphor. The second is to use this alternative conceptual framework to investigate transitions from elite sporting environments to other spheres. The final objective is to consider the broader theoretical and practical implications of the alternative for sport professionals. The central question addressed in this article is how learning in elite sport affects participation in activities beyond sporting settings. In answering this question, we present empirical material generated from in-depth, semi-structured interviews with retired Olympic athletes. First though, we describe the conceptual framework that we used to analyze the topic and outline the data production procedures in more detail.

\section{THINKING ABOUT MOVING: A RECONSTRUCTION APPROACH TO LEARNING ACROSS BOUNDARIES}

It is worth reflecting on why life skills and the ideas of acquisition and transfer in and through sport have proven persuasive. Transferrable life skills fit comfortably within traditional understandings of sport for a variety of reasons. First, the idea that sport prepares participants for life has a long history. A significant rationale for sports' place in the public schools of England in the nineteenth century was the preparation they provided boys for 
adulthood [20]. In this sense, today's ideas have a degree of historical continuity. Second, a focus on life skills corresponds with 'toolbox' approaches to sport. Within this perspective, psychological skills are conceptually analogous to physical ones and athletes may procure both as they progress through their careers. Third, the idea of life skill development is consistent with a transactional perspective where individuals invest in sport for a return. Again, this relatively typical view is reflected in the professional organization of elite sport where time and resources are traded for symbolic and material commodities. Incidentally, it is also reflected in people's rationales for doing recreational sport - many invest in sport for health returns [21]. Lastly, an increasing interest in life skills parallels current interest in holistic approaches to athletic development [22, 23]. Indeed, Stambulova et al. suggest that one of the major trends in applied sport psychology has been a shift to a "holistic lifespan perspective" [24, p. 95]. Coaches and sporting organizations are increasingly taking responsibility for athletes' lives beyond sport and offer programs to help athletes once they finish [25].

Irrespective of intuitive appeal, an acquisition and transfer theory of learning is metaphoric [26, 27]. It is just one, albeit dominant, way of conceptualizing learning. It is based on a metaphor of 'learner as vessel'. Learners 'fill up' with knowledge/skills in one context, perhaps a formal educational institute like a university - in our case a sport setting - and then take these knowledge(s)/skills to other contexts where they put them to use. Knowledge(s)/skills comprise a kind of substance that is separate from both the context in which it is learned and the person who acquires it. Hager and Hodkinson [19] argue that the conceptual disconnection of skills from context is crucial if different people are to be seen to learn skills in one situation and utilize them in another. Goal-setting skills acquired in a sport setting for instance, must be seen as universal and generic if they are to be considered applicable to other situations such as employment.

Significantly, this thinking aligns with many traditional education practices [18, 28]. Indeed, Beckett and Hager [29] contend that this has become the "standard paradigm of learning" [p. 98]. A substantial problem however, is that acquisition and transfer thinking fits poorly with experiences of transitions $[19,30]$. Such theories do not illuminate for example, how or why people finish similar learning experiences with different skills or knowledge. Nor do they explain how some educational experiences, especially protracted experiences, result in changes that are much deeper and difficult to recognize than a set of skills. In these cases, a focus on skills frames learning too narrowly. Learning theorists have also pointed out that acquisition/transfer explanations ignore that few transitions allow for skills to be directly transplanted [18]. Transitioning almost always requires adaptation or modification of skills/knowledge meaning that the explanatory power of transfer theories often needs to be qualified or tempered.

Alternative theoretical approaches to transitions do exist. We are going to draw from a corpus of literature that frames learning across contexts as moving and becoming $[19,31$, 32]. Rather than seeing learning in terms of acquisition and transfer, this conceptual framework is grounded in a reconstruction metaphor. Importantly, we do not present this theoretical impulse as a replacement for transfer thinking but like Sfard [27], consider it complementary. It is generative in the sense that it provides a different way of looking at a phenomenon and provides new aspects for consideration.

Within this line of thought, learning is matter of reconstructing oneself. From a reconstructionist perspective, individuals are considered members of networks that are held together by social relationships [32]. Learning is conceptualized as movement within a network. When individuals move within a network, their relationships to others change. In 
this sense, learning is moving is changing relationships. It involves taking on new ways of acting, speaking and valuing.

To capture the way an individual talks/acts/thinks/values as an analytic term, several scholars have drawn on Bourdieu's notion of disposition [19, 30]. A disposition refers to how a person generally manages his or her relationships with others. They involve "deep seated orientations that strongly influence actions" [19, p. 631]. In this sense, dispositions become typical or habitual ways of relating to other people. A disposition involves how one holds one's self, how one dresses, how one talks, what one values. Learning can include changes to any element of one's disposition.

Dispositions may be deep seated but because people are part of multiple and shifting networks, they are not entirely fixed. Further, the positions that individuals take within networks are not only dependent on their dispositions but also on the other people in those networks: individuals cannot simply adopt new positions; they need to be granted them. In this sense, becoming 'someone else' is limited and facilitated by the people around an individual. This precept is related to expectations and again, this is key in a sociocultural approach. Granting of positions can be considered at a local level. Take for example a team member that is accorded the position of team captain because she has played the most games. There is an expectation that not only can she do the job but that she deserves it. Expectations can also work at a cultural level. In Western European and North American countries for example, it is sometimes expected that Eastern European and Russian coaches will be tough and successful in particular sports. Such expectations have consequences for these coaches if they move to Western Europe or North America in terms of what they do and the relationships they develop, regardless of whether they are tough and successful. The expectations that surround a position are never absolute - not everyone will believe that Russian coaches are tough. Nor will all people react in the same ways to a given position. It is this reflexivity that makes social phenomena complex and difficult to predict.

A final point relates to the literal and metaphoric nature of movement. One does not necessarily have to move geographically to a new network to become someone different. One can stay in the same place and develop new relationships and therefore a new position within the same network. Nor does a different network necessarily constitute an entirely different set of social relations and therefore significant learning. An athlete could change the club she plays for but find herself in the same kinds of relationships with team mates and administrative personnel as she had at her former club.

These ideas have relevance to considerations of athlete career transitions and as we have suggested, a reconstruction approach to learning directs our attention to different aspects than a traditional acquisition and transfer perspective. In the second part of the article we are going to explore some elements of transitions that a reconstruction framework brings into focus. Following this, we will examine alternative courses of action this framework offers. First, however, we outline the procedures we used to generate data.

\section{METHOD}

In trying to understand the dispositions developed in and after elite sporting participation, we interviewed Olympians. Interviewing allowed us to investigate the kinds of relationships the athletes developed and the practices that were commonplace in and out of elite sporting communities. The specific procedures for data production are described below.

\section{RESEARCH DESIGN}

The current investigation was interpretive in nature in that the goal was to understand how 
athletes described themselves in different contexts. A multiple-case design [33] was employed where eight athletes were investigated and each individual athlete served as a unit of analysis. Because the purpose of the investigation was to see what a reconstruction theory of learning could bring into focus in particular cases rather than test the veracity of the theory for elite athletes in general, extracts from three of the cases are presented (in other words, not all empirical material is presented here). Any of the cases could have been selected since they all permitted a reconstructionist reading and the same methods were used to generate data for each of the cases. The cases that follow have been chosen because they show the development of diverse dispositions and hence give a sense of the different kinds of learning that take place in and beyond sport. The decision to present three was crucial because it allowed us to deal with the participants' commentaries in sufficient depth. As Yin [33] suggests, a case study approach is useful because it facilitates a focus on process. As we will suggest, the value of the resulting arguments lies not in their statistical significance but in their 'social significance' [34]. By this, we mean that we are not relying on the number of cases to support the importance of our arguments but on the insights they produce.

\section{SAMPLING/RECRUITMENT}

We wanted to interview individuals that had trained for and competed at the Olympics (Winter or Summer) since performance at this level would involve substantial commitment to the development of elite athletic dispositions and thorough immersion in elite sporting cultures. We were especially interested in individuals that had competed in the last seven years and had since retired. We assumed that this time frame would be long enough to capture the process of moving away from sport and into other spheres, but short enough to ensure that individuals could recollect the events in the process with precision. As is sometimes the case with sampling, access played a significant role [35] and we worked with individuals from our respective countries of residence (Australia, England, Switzerland and Sweden) who were willing to take part in the project. In line with our attempts to protect anonymity, the nationalities of the three athletes presented in this paper remain unstated (see below). The international sample did provide an opportunity to examine the influence of socio-historical and political factors on transitions (see for example, Stambulova and Alfermann [36] for a thoughtful discussion of a cultural psychological approach). The current investigation, however, did not attempt to capture such factors and has the more modest aim of examining local sporting cultures in terms of people and interactions.

Possible participants were contacted via e-mail through sport institutions. They received information about the nature of the investigation and an invitation to take part. If the individuals accepted, interviews were scheduled for times and places of the individuals' choices. Informed consent was obtained from all participants. Participants were also informed that anonymity could not be guaranteed (given the specialized nature of their experiences) but that efforts would be made to make identification difficult. These efforts included using pseudonyms and minimizing identifying information. Participants were provided with an opportunity to check material intended for publication and remove personal comments if they felt necessary. The requirements of the ethical review panels were met in each of the respective research locations.

\section{DATA PRODUCTION PROCEDURES}

Two semi-structured interviews [37] were held with the athletes, with each lasting approximately 1.5 hours. The first interview covered topics relating to athletic career progression, learning and social relationships. The schedule included questions such as: 
"How did your sporting participation change over time?", "What did you need to learn in order to do well in the sport?", and "Who was important to you in your sporting context?" After the interviews had been transcribed, and in line with Alvesson and Skoldberg's [38] notion of reflexive methodology, the athletes were interviewed a second time using material from the first conversations as prompts. The interview material that is presented below comes from interviews that took place in English.

\section{ANALYSIS AS PRACTICAL ACTIVITY}

Interviews were transcribed and examined independently of one another. Once data were structured thematically, each theme was examined more closely. This involved multiple readings and note taking. Annotated transcript excerpts were developed into written interpretations. Writing with and about the transcripts functioned as a method of inquiry [39]. Analysis then contained a collective element. Dialogue took place between the four researchers, facilitating reflection. Discussion centered on the nature and meaning of the athletes' statements and led to alternative and more reflected ways of understanding the data. Importantly, collaboration was not used as a triangulation-type strategy to ensure convergent interpretations but as a way to explore divergent and competing explanations. At the same time, our approach to the transcripts was more realist in nature, in that we have largely accepted the accounts at face value and have not attempted to connect the interview to its socio-historical/political context [40], nor have we tried to attend to the narrative structure or linguistic features of the commentaries (cf., Carless and Douglas [7]).

\section{RESULTS}

In presenting empirical material, we have focused on elements of dispositions that appeared significant within the participants' own accounts. The orientations presented are consequently ones to which the participants attached importance. In saying this, the descriptions that appear below constitute our interpretations since we have chosen what to include and how to present it. It is not our intention to advance an assessment of the dispositions, a point to which we shall return. At the same time, the accounts ask us to think about orientations elite sport participation can create and the consequences learning has for individuals after sport.

\section{ROGER: COMBAT SPORT}

Roger was involved in a combat sport from the age of seven. He began specializing in the sport at 15 and was entering international competitions soon afterwards. He eventually competed at three Olympic Games. After a surprise defeat at his second Olympics he reached the podium at his third Games, a result that he indicated enabled him to finish elite competition at peace with himself. During his career, Roger studied sport sciences part-time. Since finishing his athletic career he has concentrated on completing his tertiary education and coached and coordinated at his club. As a result, he has not moved from elite sport into one field but into several fields in which he was already partially participating.

For Roger, a key element of becoming an elite sportsperson was learning to be egotistic or selfish. He explained how this did not come naturally to most people, and believed it was something that an athlete must learn to perform well:

Sport is like this: when you do competition sport, you think about you, what I'm going to do to beat my opponent. That's it. You have to think like that. 
He described how getting his own way in competition was essential, using the metaphor of making one's voice heard over others. This self-centeredness was supported by the relationships within his sporting network. Roger had an extensive "entourage" that (sometimes voluntarily) invested vast amounts of time and money into his performance. He commented that if he wanted advice or support of any kind, he knew where he could get it. While it is difficult to say with certainty, this self-centeredness seemed to be related to Roger's difficulty finding training partners in the latter stages of his career.

It is also worth noting here that Roger uses the general pronoun 'you', generalizing his own experience to the typical elite sport experience. This feature gives the account the rulelike impression of certainty and at the same time, helps to grant the speaker expert status. This may have been the result of the interview context (i.e., a professional sports person talking to a non-professional sports person) or it may have been due to Roger's success (i.e., he felt that his Olympic medal entitled him to say how one does it). In either case, this was a recurring feature both in Roger's interviews and those of the other athletes.

The relevance of egotism in managing relationships with others after sport was evident in Roger's interview. He did not see coaching as a long-term career option because it involved too much personal sacrifice. Despite knowledge, contacts and opportunities, he was reluctant to move from an elite athlete position to a full coaching position. He acknowledged that as an athlete, he had occupied a privileged position in his community with a distinct set of relations to others. Coaching would involve a very different set of relations and Roger maintained that a transition to this position would be difficult. He specifically stated that coaching would involve substantial amounts of time in gyms and travelling to competitions, and he was not prepared to occupy this kind of 'benefactor' position, especially as he felt the chances of success were slim.

At the same time, his account of transitioning to part-time coach revealed a process of reconstruction where he had learned to approach relationships less egotistically. During coaching activities, there were times when his charges did not want to train as he wanted and he had to change. Roger explained that there was a difference between being an elite sportsperson and simply being a person:

If you quit and you retire from sport, you can't only think like this and you are not alone anymore, and it's not only going on success or that you win. You are living with other people and you have to socialize or whatever. It's a bit more complex.

Still, reconstructing himself and his relationships was extremely difficult. It is significant that he referred to compromise as the "hardest thing [he had] ever had to do" and that dispositional change was driven by the expectations placed upon him by the novice participants, rather than by Roger himself.

Roger's commentary on the purpose of sport connected to a second dispositional element which concerned reflective distance. Roger recounted how the combat sport culture revolved around competing for recognition. He maintained however, that distancing oneself from that culture was crucial if one is to be successful:

If you want to be good and you want to be free, you have to take a distance from this. Otherwise you are in this world. Then you have the pressure. Maybe it works. You can win one time, two times. But one day it gets you. And that's one part of it that got me at the [second] Olympic Games... What happens if you fight and you lose and you don't have the recognition? You commit suicide or what? You have to find something else. 
It is not difficult to see how contemporary sports privilege rewards. Less evident is how a reflective disposition can be developed against a prevailing culture. Roger's unexpected loss at his second Olympics constituted a critical incident and his account suggested that it effectively forced him to reflect on the importance he placed on sporting success and his view of himself. Roger's commentary also suggested that although many in his wider sporting community valued recognition above all else, several members of his local practice community encouraged him to value a long-term approach to achievement. One coach urged him to take pleasure from personal improvement and not focus on medals or other athletes' achievements.

Issues of recognition emerged in Roger's account of transition. He stated that his Olympic medal affected the expectations those outside the sporting community placed upon him. He received job offers and could have accepted 'a reasonable salary' immediately after his retirement, largely by virtue of being an Olympic champion. Instead, he chose to continue his educational involvement and extend his time as student. He noted that eventually his position as Olympian would fail to influence his relations. The propensity to look past rewards was not consistently represented in his account and Roger's comments reflected not so much a rejection of material rewards as a willingness to wait for them. Indeed, remuneration seemed to affect how he managed his relations to the public and he foregrounded issues of payment on several occasions. Further, and by his admission, Roger was unsure whether he would have been satisfied with his transition from athlete to sport student/coach had he not won an Olympic medal.

\section{KARIN: TEAM SPORT}

Karin began involvement in her sport when she was seven. She was selected for various representative teams and at 12 years of age was training most days of the week. She identified the age of 15 as the time when she started to make sacrifices for sport. According to Karin, "that's kind of the hard time where you're kind of torn between what you want". During her sporting career, Karin completed a tertiary qualification in nutrition. She attributed her educational involvement to the influence of her family and career guidance she received while competing as an amateur. Throughout her career however, she felt that athletic personnel did not encourage participation in parallel activities and asserted that it was not typical for other national players to work or study. In the final stages of her sporting career, Karin found employment as a personal trainer. She had steadily increased her involvement in this area since she finished competing and was recently invited to take on management duties at the personal training company in which she worked. Recently, she has had a baby and separated from her husband. She describes herself first and foremost as a single mother.

An orientation that emerged clearly from Karin's account concerned determination. She recounted various practices that tested her and her colleagues' resolve to be elite athletes and in an effective illustration of how participants of sporting communities both provide and deny particular positions for others, recounted several anecdotes of how community members were involved in practices that encouraged player withdrawal. Male staff for example, conducted skinfold tests on the female players each week, publicly announcing each individual's result. Players with higher measures were put into a special "fat club". In a pseudo-Darwinist manner, players within the national team tested each other, both physically and emotionally during training and in the process created a hierarchical set of relationships based on aggression: 
Interviewee: [the older players] were very threatened by young people coming through and taking their position. So yes, they'd do all sorts of nasty things.

Facilitator: What sorts of things?

Interviewee: Oh just, you know, there'd be training and the young girls you'd get, you'd have to have a strong mind because they'd say stuff and they'd hurt you.

Facilitator: Like, physically?

Interviewee: Yes, physically, you know.

While a number of players "crumbled", essentially abandoning their positions within the national team, Karin repeatedly said that she was willing to "do everything she could" to be in the team. She displayed the characteristics necessary to occupy a 'member' position. She described this as the "determination to make it no matter what", adding that,

I saw so many things that were so worrying. But it's just disregarded because if you want to make this team you've got to do it.

After finishing sport however, Karin appeared to have uncoupled the practices of her elite sporting community from what she called "real life". She said on a number of occasions that competition is unique:

You're in this bubble of elite sport, you know, and it's really not that normal at all. It's very unnatural but to you, it's normal.

And later:

Having a child puts everything into perspective and you're no longer in your stupid little bubble of yours. Selfish bubble.

This uncoupling was associated with a change in disposition. Her commentary suggested that she would no longer participate in such practices. Indeed, she was reluctant to return to the sport as a coach. This is not to say that she was no longer determined (her account of working motherhood certainly reflected a determination-orientation), but rather she wanted to avoid re-entering a similar network of relations where she might have to take part in practices that she did not condone.

A second orientation related to a willingness to live a highly structured life. On a number of occasions, Karin referred to "professionalism". This was a concept that extended beyond sport and encompassed training and competition regimes, eating habits, recreational activities and contact with friends and family. She said, for example:

We were exposed to nutrition classes and cooking and setting goals and aims, like back then we were 13. So it's already kind of hammered into you...There's a program, every day you'd have to be doing something. You'd be like meeting, training, like everything - there's a structure, a structure and plan to everything, and you have to follow that... I'm still like that and it becomes habit.

Perhaps a first point to note is that Karin herself assigned continuity to this disposition. Despite finishing sport, she claimed to have remained highly structured. Later in her commentary she again said that sport was "very, very planned and organized" and that even though it "drives [her] nuts" she is still like that. This orientation appeared to be related to her decision to try out for the national squad after one year of retirement. One of the main 
advantages of returning for Karin was that her life was planned again - she did not have to think about anything else.

This dispositional continuity was facilitated, we would argue, by her current employment and familial relationships. Her job as personal trainer required her to schedule training sessions early in the mornings, organize childcare in advance and carefully plan social commitments. Hence there was a significant temporal dimension that needed to be managed for practically all of her relations. Indeed, Karin stressed that her 'program' as working mother required structure and planning and she underscored the need to be organized. Importantly, a significant part of Karin's job is helping people to organize and structure their lives:

It's always been drilled into you. Now it's funny, things that I think are so everyday, people are still struggling to understand. Sometimes that's so hard because it's such a learning process for them whereas it's just habit for you and you don't think anything of it.

In some ways, this comment shows relatively simply the difference between learning as skill acquisition and learning as becoming. In Karin's sporting situation, practices such as getting up early and monitoring her diet had become part of who she was. Further, they were thoroughly supported by her coaches and her teammates (several of whom she was living with at the time). In her new situation, she was dealing with clients that were not living in elite sporting communities and who had neither similar kinds of relationships with those around them nor the same organized, structured disposition. As a result, simply telling individuals how to do the things that she had become used to doing (i.e., 'giving them tools') was ineffective. This was because the learning Karin experienced had involved much more than learning how to do, it had meant learning how to be.

\section{EMMA: TEAM SPORT}

Emma began participation in her sport while she was in primary school. She was selected for a state representative team at 11 and a national age-group team at 16. It was only over time that she came to believe that she deserved a place in the national team and she eventually competed at three Olympics. She remarked that she had always managed to keep sport in perspective and recalled that her coaches did not like it when she once said that "it's just a game". Indeed, she recognized this point of view as significantly different from that of her coaches and teammates and indicated that this posed a risk. She suggested that it was necessary to act like her sport was the most important activity in her life while she was in her sporting context if she was to maintain her position within that community. Her references to time spent with family, however, provide an indication of the different community values that influenced her and go some way to explaining how she came to find herself at odds with the all-or-nothing perspective that inhered in her sport.

Given her kind of dual-perspective, it is somewhat paradoxical that of the athletes in the study, she provided the most negative account of transitioning. She described experiencing depression and anxiety for more than a year after retirement from sport, labeling her condition as "debilitating". She maintained that her transition from sportsperson within a sporting network to primary school teacher was especially difficult.

Aspects of Emma's disposition emerged in her explanation of her career and her transition. She stated that a perfectionist approach was critical for her own success in sport. She said that she: 
Loved perfecting intricate skills. It never bored me. I loved that. Just by the end it was... you're trying to tweak the smallest little thing and I really enjoyed that.

Attention to detail was embedded in the sport's practices ranging from physical and technical training to the selection of materials to corporeal monitoring. Combined, these measurement practices contributed to a particular orientation in which small details mattered and the consequence of every action could be counted. Emma explained that,

In [my sport] you would be training for some intricate little skill that you want to improve or perfect and you had constant goals and you had constant reassurances that you were doing the right thing.

This comment is particularly illustrative because it shows that what she liked about perfection was: 1) that efforts are recognized by those in her immediate community, and 2) that it is clear what should be done. These were recurring features in Emma's interviews. By her third Olympics, she realized that she needed to have her efforts recognized by the coach to perform well:

I don't care if I'm needy - tell me I'm shit hot if that's going to make me play better.

Her employment setting was significantly different from sport and thus necessitated substantial learning. Reflecting on her work as a primary school teacher she said:

I went to teaching and there's no feedback really. There's 12 year-olds telling you to, you know... I had no measure of how I was going or was I going in the right direction or. Of course as an athlete you have very high expectations, so I want to know that it's going to be there in a fast manner. I kind of thought, I was overwhelmed by the fact that this wasn't true anymore.

While Emma dismisses the presence of feedback in her lessons, we would propose that it was not feedback in general that was missing during her teaching but the specific, precise feedback to which she had become accustomed (compare the kinds of behavioral and highly differentiated feedback that teachers receive in their relationships with pupils with the precise, immediate feedback that comes with performing many motor skills). At school, the absence of explicit success markers led to a profound kind of confusion where the disposition that had once proven so useful lost its utility. It is noteworthy that she said that what was once true had become false. In sport, she could get clear, direct answers and her preparation for the Olympics could be meticulously planned. In teaching, no-one told her how to do things or how to be successful.

A second aspect that emerged was preparedness to work and wait; what Emma referred to as "doing the time". This involved not expecting things to come quickly and also accepting that things do not always run how you want them to. Emma spoke of younger players who sometimes got upset when they did not have immediate success and recalled instances where she had done the same. She also referred to experienced players that would accept failure quietly and came to admire these players. In terms of how the social network produced a change in Emma's sporting disposition then, the presence of experienced players that had secured positions on the team (members at the core of the community) showed her the kinds of values and behaviors that were necessary and/or desirable within that environment. By 
continuing to get upset and disappointed with sporting failure, Emma risked casting herself as a novice athlete that did not belong to the core community. Her comment that by the end of her career she too was, "just much more mature and much more at ease and at peace with the whole thing" goes some way to explaining how she managed to secure a place in the team for more than eight years.

This orientation was also reflected in her approach to teaching. She said that she "was humble enough to realize that [she] wasn't going to be a great teacher in [her] first year". She suggested that, although it was daunting, it would probably take a number of years to be a really good teacher. At the same time though, Emma stated that she wanted to "see progress". In this situation, her perfectionist orientation and a reliance on clear success markers seemed to counter a potentially generative approach to employment in an educational setting. To use an analogy: it was as if Emma was prepared to drive slowly but from where she was sitting, she could not see the road.

\section{DISCUSSION}

By way of three cases, we have illustrated the kinds of aspects a theory of learning and transfer based on the notion of reconstruction might reveal about athletic transitions. Drawing from sociocultural learning theory, we have tried to understand learning that was supported in sporting contexts and how particular 'ways of being' persisted or were reconstructed across practice boundaries. What we would like to do now is make three broader arguments based on the empirical material. These relate to differences between transfer and reconstruction thinking, along with a consideration of consequences.

Thinking in terms of reconstruction as opposed to acquisition and transfer brings different aspects into focus and raises several issues. A traditional transfer perspective encourages us to see skills as assets that athletes can lose or simply choose not to use [14]. From this perspective, athletes must have a stable inner self (a personality, perhaps) that is distinct from those resources. A dispositional conceptual framework, in contrast, compels us to bring the resources and the self together [30]. Viewed in this way, individuals do not have fixed or innate personalities but rather, more or less enduring ways of acting and talking that are developed in relation to social environments over time. This second perspective fits with the empirical material in that the athletes appeared not to consciously choose to employ 'strategies' but instead came to embody particular ways of being. Roger could not switch on and off his orientation towards rewards, nor could Karin simply become disorganized, even if her tendency to be highly organized sometimes drove her "nuts". This perspective also fits with more recent understandings of retirement as a transitional phase or process that occurs over time rather than a one-off, bounded event $[8,41]$.

While these orientations may have been persistent, they were not fixed and the athletes did recount examples of change. Here, the social contexts into which the athletes moved played important roles in enabling and prompting change. In Roger's case, his relationship with the young people that he coached was critical in his attempt to move away from an egocentric disposition and a performance culture in which other members were result oriented (cf., the athletes' narratives in Carless and Douglas' [7] work). Similarly, Emma experienced tensions between her sporting disposition and her new environment most acutely when dealing with young people. The disjunction between her experiences and what she was experiencing during lessons could be referred to as a kind of "narrative wreckage" [8, p. 220] where things started to make little sense and her sense of self was threatened. This incoherence impelled her to seek counsel with a psychologist and the principal of the school in which she worked. Karin's learning was affected somewhat differently by her new social 
context. Her tendency to be highly organized proved productive in her new set of relationships and she noted how her superior had rewarded her capacity for management by inviting her to take on more responsibility within the company. At the same time, the birth of a child along with the departure of the father of that child had substantially affected her position within her familial community. Although this topic remained relatively unexplored during the interviews, the child's birth appeared to result in a restructuring of values and identity and towards alignment with Western cultural expectations of the 'good mother' [8]. According to Karin, the birth of her child contributed to her lessening determination to work in an entirely focused manner towards a goal.

Even if the athletes did not choose to describe their moves as descents into "the mundane world of ordinariness" [4, p. 644], their accounts did underscore the effort, for want of a better word, involved in adapting to new settings. When the athletes moved to new networks, they were faced with the challenge (and the opportunity) of developing new sets of relationships. Here, it is useful to think about the difference between moving in a literal sense and moving as becoming someone else [19]. Theoretically, it is possible to literally move but not develop new ways of interacting with others (metaphorical move). In Roger's, Emma's and Karin's accounts, departures from athlete positions located within networks of team mates, coaches and a raft of others and arrival in new positions as coaches, teachers or personal trainers in different contexts did result in learning and it did require work. Karin, for example, was faced with the challenge of constructing a mother 'position' as well a different set of professional relationships as she took on an instructor position for individuals wanting to improve their health and fitness. Despite her comment that having a child enabled her to 'burst out of the bubble of elite sport' (and notwithstanding her own ability to live a structured life), she found her position as instructor required substantial change in the ways that she related to people. In fact, she seemed to still be working at understanding her clients and their entirely different way of seeing fitness and exercise at the time of the interviews. Roger's claim that learning to compromise was one of the hardest things he has had to do also attests to the work that was required in changing positions. Tensions arose when a move was not accompanied by a dispositional shift as in Emma's case at school. In a way, while transfer thinking suggests that difficulties arise when individuals fail to bring elements from their old setting to the new, reconstruction thinking suggests that problems are more likely to occur when individuals continue to embody elements from their old setting that are inconsistent with expectations of the new (here we are reminded of McKenna and Thomas' [9] evocative case study of a professional rugby player that struggled to disengage with his sporting career).

A related point concerns the positive connotations of skill transfer that are supported in much of the sport transition literature [e.g., 11, 16]. Skills and assets are generally helpful and the terms imply that learning is inherently positive. A reconstruction approach encourages us to suspend evaluation and reflect on the process of becoming. In each of the cases, the dispositions developed in sport could have proven useful afterwards. Emma's perfectionistic orientation could have been useful had she entered a setting where the goals were clear and she could receive regular feedback - perhaps if she had gone on to further study. Karin's determination and willingness to ignore practices that she found morally troubling could also have served her in other contexts. We would contend that labeling learning as inherently, or absolutely, positive or negative is not that helpful. We are more inclined to think in terms of 'contextual productivity' - see Hodkinson, Biesta and James [30] for a similar argument. By contextual productivity we mean how well a disposition matches the expectations placed upon the individual in a new identity. This is not to say that 
we do not make ethical evaluations of the dispositions. Roger's claims of egotism certainly evoked an emotional response from us and we agreed with his claim that one can rarely think only of oneself. Similarly, Karin's capacity to submit herself to dehumanizing practices in the name of sporting success at the very least deserves some consideration. But potential responses are grounded in specific cultural notions about ethical behavior and how individuals should relate to others, rather than the athletes' local situations where what was good and bad were defined and negotiated.

Finally, in contrast to acquisition and transfer thinking, a reconstructive approach brings into focus unintended learning - see also Hodkinson and Hodkinson [31]. The kinds of dispositions that were described in these accounts were not set out in a program. None of the athletes claimed that they were explicitly encouraged to ignore instances of personal putdowns or to focus on intricate details of motor skills, for example. Instead, dispositions developed with particular positions in given constellations of people and relationships. For a coach interested in preparing athletes for worlds beyond sports careers, a reconstructive approach does not seem to offer the concrete practical suggestions that life skills programs [42] seem to offer. We would propose, however, that the approach also has the potential to steer our actions. Practitioners and theorists interested in holistic learning [22, 23] might concentrate on how the practices of sporting communities support the development of certain kinds of dispositions. For example, we might examine how giving continuous and extensive feedback may result in individuals that are reliant on explicit responses. Or we might look at how creating training environments that place one athlete at the center of a large group's efforts may produce individuals that are self-centered. Or we might consider how the initiation of intra-team rivalry practices might increase performance but at the same time make connecting to communities beyond sport difficult, both during and after athletic careers. This kind of (local) culturally-oriented perspective has similarities with Stambulova's [13] approach to holistic learning, especially in its focus on past experiences and the consequences these have for the future. It does however, lay greater emphasis on culture and everyday interactions than on specific events and the capabilities of the individual.

\section{CONCLUSION}

End-of-career transitions can be understood as a process of personal reconstruction. When athletes leave sport, they re-negotiate their dispositions and develop new ways of interacting with others and the world around them. The cases above encourage practitioners to acknowledge the effort involved in this process. They invite us to consider the challenges of giving up ways of talking/acting/seeing/valuing that have become embedded within the person and the coinciding challenge that athletes will face of developing new ways of talking/acting/seeing/valuing in different networks.

The differences in the cases support a case specific view of transitions where 'successful learning' is considered in contextual terms rather than in universal terms. The productivity or usefulness of dispositional elements is a function of both the learning that takes place during sport and the context into which the individual moves. This makes broad, evaluative conclusions regarding the nature of learning in elite sport difficult and consideration of the specific characteristics of individual's circumstances essential.

Finally, the data highlight a need for sport professionals working with elite athletes to recognize learning that inheres in sporting environments. This is crucial if they are to have the capacity to influence it. Without acknowledging the kinds of learning that inhere in our own interactions, our training schedules and routines, our systems of recognition and our 
physical environments to make just a few examples, it will be difficult to help individuals to move across boundaries and participate in other practices effectively.

\section{ACKNOWLEDGEMENT}

We would like to thank both reviewers for their thought-provoking comments. This research was financed by the 2011 IOC Postgraduate Research Grant.

\section{REFERENCES}

1. Alfermann, D., Stambulova, N. and Zemaityte, A., Reactions to Sport Career Termination: A Cross-National Comparison of German, Lithuanian, and Russian Athletes, Psychology of Sport and Exercise, 2004, 5, 6175.

2. Conzelmann, A., and Nagel, S., Professional Careers of German Olympic Athletes, International Review for the Sociology of Sport, 2003, 38(3), 259-280.

3. Lavallee, D. and Wylleman, P., eds., Career Transitions in Sport: International Perspectives, Fitness Information Technology, Morgantown, WV, 2000.

4. Sparkes, A.C., Athletic Identity: An Achilles' Heel to the Survival of Self, Qualitative Health Research, 1998, 8(5), 644-664.

5. Stephan, Y., Bilard, J., Ninot, G., and Delignieres, D., Bodily Transition Out of Elite Sport: A One-Year Study of Physical Self and Global Self-Esteem Among Transitional Athletes, International Journal of Sport and Exercise Psychology, 2003, 1(2), 192-207.

6. Nagel, S., Medaillen im Sport: Erfolg im Beruf? [Medals in Sport: Professional Success?]. Hofmann, Schorndorf, Germany, 2002.

7. Carless, D. and Douglas, K., 'We Haven't Got a Seat on the Bus for You' or 'All the Seats are Mine': Narratives and Career Transition in Professional Golf, Qualitative Research in Sport and Exercise, 2009, 1(1), 51-66.

8. Douglas, K. and Carless, D., Abandoning the Performance Narrative: Two Women's Stories of Transition from Professional Sport, Journal of Applied Sport Psychology, 2009, 21(2), 213-230.

9. McKenna, J., and Thomas, H., Enduring Injustice: A Case Study of Retirement from Professional Rugby Union, Sport, Education and Society, 2007, 12(1), 19-35.

10. Wylleman, P.P., and Reints, A.A., A Lifespan Perspective on the Career of Talented and Elite Ethletes: Perspectives on High-Intensity Sports, Scandinavian Journal of Medicine \& Science in Sports, 2010, 20(Suppl. 2), 88-94.

11. Jones, M., and Lavallee, D., Exploring Perceived Life Skills Development and Participation in Sport, Qualitative Research in Sport and Exercise, 2009, 1(1), 36-50.

12. Lavallee, D. and Andersen, M., Leaving Sport: Easing Career Transitions, in Andersen, M., ed, Doing Sport Psychology, Human Kinetics, Champaign, IL, 2000, 223-236.

13. Stambulova, N., Counseling Athletes in Career Transitions: The Five-Step Career Planning Strategy, Journal of Sport Psychology in Action, 2010, 1, 95-105.

14. Bodey, K., Schaumleffel, N., Zakrajsek, R. and Joseph, S., A Strategy for Coaches to Develop Life Skills in Youth Sport, Journal of Youth Sport, 2009, 4(2), 16-20.

15. Gould, D., Collins, K., Lauer, L., and Chung, Y., Coaching Lifeskills Through Football: A Study of Award Winning High School Coaches, Journal of Applied Sport Psychology, 2007, 19(1), 16-37.

16. Alfermann, D. and Stambulova, N., Career Transitions and Career Termination, in: Tenebaum G. and Eklund, R., eds., Handbook of Sport Psychology, John Wiley, Hoboken, NJ, 2007, 712-733.

17. Weinberg, R.S. and McDermott, M., A Comparative Analysis of Sport and Business Organizations: Factors Perceived as Critical for Organizational Success. Journal of Applied Sport Psychology, 2002, 14, 282-298.

18. Beach, K. Consequential Transitions: A Sociocultural Expedition Beyond Transfer in Education, Review of Research in Education, 1999, 24(1), 101-139.

19. Hager, P. and Hodkinson, P., Moving Beyond the Metaphor of Transfer of Learning, British Educational Research Journal, 2009, 35(4), 619-638. 
20. Mangan, J.A., Athleticism in the Victorian and Edwardian Public School:The Emergence and Consolidation of an Educational Ideology, Frank Cass, London, 2000.

21. Gard, M. and Wright, J., The Obesity Epidemic: Science, Morality, and Ideology, Routledge London, 2005.

22. Cassidy, T., Jones, R.L., and Potrac, P., Understanding Sports Coaching: The Social, Cultural and Pedagogical Foundations of Coaching Practice, Routledge, London, 2009.

23. Potrac, P., Brewer, C.J., Jones, R.L., Armour, K.M., and Hoff, J., Towards an Holistic Understanding of the Coaching Process, Quest, 2000, 52, 186-199.

24. Stambulova, N., Alfermann, D., Statler, T., and Côté, J., ISSP Position Stand:Career Development and Transitions of Athletes, International Journal of Sport \& Exercise Psychology, 2009, 7, 395-412.

25. North, J. and Lavallee, D., An Investigation of Potential Users of Career and Education Services in the United Kingdom, Psychology of Sport and Exercise, 2004, 5, 34-53.

26. Lave, J. and Wenger, E., Situated Learning: Legitimate Peripheral Participation in Communitities of Practice, Cambridge University Press, New York, 1991.

27. Sfard, A., On Two Metaphors for Learning and the Dangers of Choosing Just One, Educational Researcher, 1998, 27(2), 4-13.

28. Lave, J., The Culture of Acquisition and the Practice of Understanding, in: Kirschner, D. and Whitson, J.A., eds., Situated Cognition: Social, Semiotic and Psychological Perspectives, Erlbaum, Mahwah, NJ, 1997, 1736.

29. Beckett, D. and Hager, P., Life, Work and Learning: Practice in Postmodernity, Routledge, London, 2002.

30. Hodkinson, P., Biesta, G., and James, D., Understanding Learning Culturally: Overcoming the Dualism Between Social and Individual Views of Learning, Vocations and Learning, 2008, 1(1), 27-47.

31. Hodkinson, H., and Hodkinson, P., Rethinking the Concept of Community of Practice in Relation to Schoolteachers' Workplace Learning, International Journal of Training and Development, 2004, 8(1), 21-31.

32. Hodkinson, P., Biesta, G., and James, D., Understanding Learning Cultures, Educational Review, 2007, 59(4), 415-427.

33. Yin, R.K., Case Study Research: Design and Methods, Sage, Thousand Oaks, CA, 2003.

34. Gobo, G., Sampling, Representativeness and Generalizability, in: Seale, C., Gobo, G., Gubrium, J. and Silverman, D., eds., Qualitative Research Practice, Sage, London, 2004, 405-426.

35. Charmaz, K. Grounded Theory in the 21st Century: Applications for Advancing Social Justice Studies, in Denzin, N. and Lincoln, Y., eds., The Sage Handbook of Qualitative Research, Sage, Thousand Oaks, CA, 2005, 507-536.

36. Stambulova, N. B., and Alfermann, D., Putting Culture into Context: Cultural and Cross-Cultural Perspectives in Career Development and Transition Research and Practice, International Journal of Sport \& Exercise Psychology, 2009, 7, 292-308.

37. Rapley, T., Interviews, in: Seale C., Gobo, G., Gubrium, J. and Silverman, D., eds., Qualitative Research Practice, Sage, London, 2004, 15-33.

38. Alvesson, M. and Skoldberg, K., Reflexive Methodology, Sage, London, 2000.

39. Richardson, L. and Adams St Pierre, E., Writing: A Method of Inquiry, in: Denzin, N. and Lincoln, Y., eds., The Sage Handbook of Qualitative Research, Sage, Thousand Oaks, CA, 2005, 959-978.

40. Fontana, A. and Frey, J., The Interview: From Neutral Stance to Political Involvement, in: Denzin, N. and Lincoln, Y., eds., The Sage Handbook of Qualitative Research, Sage, Thousand Oaks, CA, 2005, 695-728.

41. Wylleman, P.P., Alfermann, D. and Lavallee, D., Career Transitions in Sport: European Perspectives, Psychology of Sport and Exercise, 2004, 5, 7-20.

42. Papacharisis, V., Goudas, M., Danish, S., and Theodorakis, Y., The Effectiveness of Teaching a Life Skills Program in a Sport Context, Journal of Applied Sport Psychology, 2005, 17(3), 247. 